\title{
Factors influencing perceived health status among elderly workers: occupational stress, frailty, sleep quality, and motives for food choices
}

This article was published in the following Dove Press journal:

Clinical Interventions in Aging

Jiyeon $\mathrm{Ha}^{\mathrm{l}}$

Juah $\mathrm{Kim}^{2}$

'College of Nursing, Konyang University, Daejeon 35365, South Korea;

${ }^{2}$ Department of Nursing, Korea Armed Forces Nursing Academy, Daejeon

34059, South Korea
Correspondence: Juah Kim

Department of Nursing, Korea Armed

Forces Nursing Academy, 90 Jaun-ro,

Yuseong-gu, Daejeon 34059, South Korea

$\mathrm{Tel}+82426008583$

Email booa04@gmail.com
Purpose: The aim of this study was to investigate occupational stress, frailty, sleep quality, and motives for food choices as key factors affecting the perceived health status among elderly workers.

Methods: A cross-sectional survey was conducted involving 175 participants at the Community Senior Club in an urban area. The data was collected from November to December 2018. Pearson's correlation analyses were performed for perceived health status, occupational stress, sleep quality, and motives for food choices. Multivariate linear regression was adjusted for general characteristics such as age, gender, level of education, living arrangements, and the number of illnesses.

Results: Occupational stress $(r=-0.195, p<0.001)$, frailty $(r=-0.468, p<0.001)$, and sleep quality scores $(r=-0.306, p<0.001)$ showed significant negative correlations with perceived health status. Conversely, 5 motives for food choices (health, weight control, price, sensory appeal, and mood) were positively correlated with perceived health status. Linear regression analysis showed that occupational stress $(\beta=-0.195, p<0.001)$, frailty $(\beta=-0.420, p<0.001)$, and motives for food choices based on sensory appeal $(\beta=0.240, p<0.001)$ were significant influencing factors for perceived health status.

Conclusion: We found that occupational stress, frailty, and motives for food choices based on sensory appeal were significant factors for elderly worker health. This suggests that it is important to consider occupational stress, frailty, and motivation for food choices when examining the health of elderly workers. There is a need for more tailored health promotion interventions when considering these factors and the elderly population.

Keywords: occupational stress, frailty, sleep, food preferences, health status

\section{Introduction}

There is a growing population of older people around the world. Among OECD countries, Japan had the highest population of people aged 65 or older at $27.7 \%$ as of 2017, with the elderly population in Germany, Greece, Italy, and Finland accounting for about 20 percent. Korea had an elderly population of only 13.8 percent in 2017 , but the number of elderly people has rapidly increased and will result in a super-aged society. ${ }^{1}$ This increase in the number of elderly people is seen in many countries, and as the population of older people increases, various social and cultural issues emerge.

The numbers of elderly workers are steadily increasing with the aging of the population. Older generations are in a situation where they are required to work due 
to an increase in life expectancy, survival, and economic needs, and most of the elderly are working for low wages and in casual employment such as cleaning, security, construction, and public work in the labor market. ${ }^{2,3}$ Many elderly workers experience occupational challenges and are aware of their vulnerability due to large physical workloads and psychological job demands. ${ }^{4}$ This poor working environment has been reported to have a negative effect on the life and health of elderly individuals. ${ }^{2}$ Inequalities arising from the vulnerability of working in these environments can lead to occupational stress. Some studies have reported on the occupational stress of elderly care workers in nursing care, ${ }^{5}$ the effects of job characteristics and participation in leisure activities of elderly workers on health, ${ }^{6}$ and the health status of elderly individuals according to changing working status. ${ }^{7}$ However, few studies have investigated the effect of occupational stress of individuals aged over 65 years. One study reported there to be more social and psychological stress when the vulnerability of the elderly within the work environment and occupational insecurity increased. ${ }^{2}$ It is necessary to confirm whether the occupational stress of elderly workers has a significant effect on their health.

Most of elderly individuals aged $\geq 65$ years were reported to have more than one chronic disease, and $74.0 \%$ had complex chronic diseases. ${ }^{3}$ Older adults with multiple chronic diseases have been reported to have a high risk of frailty that increased their dependence through inducing physical and emotional dysfunction. ${ }^{8}$ Frailty is one of the major health conditions associated with aging, and it is a term generally used to represent the decline of the adaptive capacity of the organism to poor homoeostasis in times of acute events. It increases adverse outcomes like falls, institutionalization, and mortality. ${ }^{8-10}$ Moreover, elderly workers with chronic diseases have been reported to experience physical fatigue easily, ${ }^{11}$ and age-related safety risks exist in the workplace. ${ }^{12}$ The frailty of older adults decreases their quality of life not only in terms of adverse health outcomes, such as falls, cardiovascular disease, and increased cancer incidence, but also due to admission to hospitals and nursing homes. ${ }^{8,13}$ Therefore, an assessment of frailty and its relationship to health status in elderly workers is needed.

Sleep disturbance in older adults has been shown to be prevalent and is known to be associated with physical and psychological factors. ${ }^{14}$ Sleep management is an important factor for the elderly, as nearly one-half of elderly individuals living in communities suffer from poor sleep quality. ${ }^{15}$ Poor sleep quality results in decreased memory and concentration and reduced daytime activities, ${ }^{16}$ affecting the health of elderly workers. The quality of sleep for elderly workers is important in terms of health management as high physical fatigue due to aging causes an increased risk of work accidents. ${ }^{12}$ Although the relationship between sleep and health of the elderly is widely known, there is a lack of research on the quality of sleep and health condition of elderly workers.

Food intake is closely related to health and disease in older adults. Food intake is an essential factor in improving physical function and quality of life. A change in body composition and stored energy, a loss of appetite, and difficulty in preparing meals has been shown to increase the risk of malnutrition in older adults. ${ }^{17}$ One study that examined the association between work and self-care suggested that elderly workers tended to neglect their food intake and health management due to their focus on working. ${ }^{11}$ Insufficient or inadequate food intake causes negative health problems such as frailty, decreased quality of life, and increased admission rates to nursing homes. ${ }^{18}$ Food intake and choice have been shown to be related to social context; ${ }^{19}$ therefore, we considered it necessary to identify the motives affecting elderly workers' food choices. No research has been undertaken to survey the motives for food choices in relation to the circumstances among elderly workers.

Several previous studies have investigated factors concerning frailty, quality of sleep, and food intake on health in older adults. ${ }^{8,13-18}$ However, these studies have targeted hospitalized elderly individuals living in nursing homes or with specific health problems. The numbers of elderly workers are steadily increasing with the aging of the population, and most of these elderly workers have been reported to have chronic health problems. ${ }^{20}$ A perceived health status has been suggested to be more important in explaining physical and mental consequences than an objective physical status among older adults. ${ }^{21}$ Therefore, it is essential to examine the factors that affect perceived health status to promote elderly workers' health.

This study aimed to investigate occupational stress, frailty, sleep quality, and motives for food choices in elderly workers and to identify the influencing factors on perceived health status. Information derived from this study could be useful as basic data for health education and health promotion program development for elderly workers. 


\section{Participants and methods}

\section{Participants and study procedures}

This descriptive, cross-sectional study was conducted at the Community Senior Club in Daejeon, Korea. The Community Senior Club is a special occupational agency that creates and provides jobs for elderly people by utilizing resources from the community. Data collection was conducted between November to December 2018.

The study participants comprised working elderly individuals aged $\geq 65$ years old, living in an urban area. Inclusion criteria comprised participants who had been working for at least three months and who showed no signs of significant cognitive impairment (Mini-Mental State Examination (MMSE) score, $<18$ ). Exclusion criteria included participants who had been working in a specific job dealing with heavy industries, construction sites, and hazardous materials in order to control for confounding due to the healthy worker effect. ${ }^{22}$ The healthy worker effect is a selection bias common to occupational studies. ${ }^{22}$ For recruiting participants, we displayed banners in the Community Senior Club. Those interested in participating were first required to undertake an MMSE test by an investigator to ascertain the participant's level of cognitive function. If no serious cognitive impairment was apparent, a prospective participant signed a written informed consent form following a detailed explanation of the study purpose and procedures. Information concerning written informed consent and the questionnaires was provided through face-to-face interviews to collect accurate information, involving approximately $40-50$ mins spent with each participant.

The calculated sample size, using a $G^{*}$ power version 3.1. program for linear multiple regression analysis, was 160 participants under the conditions of 8 predictor variables, a type I error of 0.05 , a power of 0.95 , and an effect size of 0.15 . We planned to collect a total of 176 participants, considering a $10 \%$ dropout rate. A total of 176 participants participated in the data collection, and all 176 participants met the cognitive requirements (MMSE score, $\geq 18$ ). Finally, data from 175 participants were analyzed for the study results, with one participant excluded due to incomplete answers.

The Institutional Review Board (IRB) of Konyang University in Korea approved this study (No. KYU2018-145-01). Written informed consent was obtained from each participant, and the privacy of participant information was assured. The participants were informed that they could terminate their participation in the study at any time and that they would not be penalized in doing so in any way. The data on participants who withdrew from participation in the study were discarded immediately.

\section{Measurements}

We collected data concerning general and health-related characteristics such as the number of chronic illnesses and the use of current medication. Additionally, occupational stress, frailty, sleep quality, motives for food choices, and perceived health status were measured using the following instruments.

Occupational stress was assessed according to 24 items listed in the Korean Occupational Stress Scale Short-Form (KOSS-SF), which is a tool that has been used to measure occupational stress among Korean elderly workers. ${ }^{23}$ The KOSS-SF included 7 domains, namely, occupational demands, insufficient occupational control, inadequate social support, occupational insecurity, organizational system, lack of reward, and occupational environment. Each item was rated on a 4-point Likert-scale ranging from 1 (not at all) to 4 (very much). Score calculation for each of the 7 domains followed the method outlined by Chang et $\mathrm{al}^{23}$ and the conversion average value of the 7 domains was used for the analysis. Choi et $\mathrm{al}^{24}$ reported Crobach's $\alpha$ was 0.84 for the KOSS-SF in their study, and Cronbach's $\alpha$ was 0.76 for the KOSS-SF in our study.

The Korean Frailty Index (KFI), developed by the Korean Geriatrics Society, was used to assess participant frailty. ${ }^{25}$ This instrument is comprised of an 8-item questionnaire involving questions regarding hospitalization, self-rated health, poly-pharmacy, weight loss, depressed mood, incontinence, the Timed Up-and-Go test (a simple test for assessing a person's mobility), and hearing or visual impairment. The total score ranges from 0 to 8 , with cutoff values between 3 and 4 for pre-frail scores and a score $\geq 5$ indicating frailty. Higher scores indicate more frailty symptoms.

The Pittsburgh Sleep Quality Index (PSQI) ${ }^{26}$ was used to assess sleep quality. This tool is comprised of 19 items and 7 sub-domains comprising subjective sleep quality, latency and duration of sleep, habitual sleep efficiency, sleep disturbances, sleeping medication, and daytime dysfunction. The higher the total score, the more negative the sleep state. A sum of $\geq 5$ is interpreted as poor quality of sleep. Cronbach's $\alpha$ was 0.83 for the $\mathrm{PSQI}^{26}$ and Cronbach's $\alpha$ was 0.74 for the PSQI in our study. 
Steptoe et $\mathrm{al}^{27}$ developed the Food Choice Questionnaire (FCQ) to measure food preference motives. This instrument is comprised of 36 items that measure the importance of 9 motives for food choices such as health, weight control, price, sensory appeal, mood, familiarity, convenience, natural content, and ethical concerns. A 7point Likert-scale was used to obtain responses to each factor domain, ranging from 1 (strongly disagree) to 7 (strongly agree). The higher the average score, the more important the motive for food choices. In our study, Cronbach's $\alpha$ was 0.93 for the FCQ.

Perceived health status was assessed using a 3-item questionnaire $^{28}$ with possible scores ranging from 1 (very bad) to 5 (very good). The higher the average score of the 3 items, the better the perceived health status. Cronbach's $\alpha$ was 0.85 when the questionnaire was developed, ${ }^{28}$ whereas Cronbach's $\alpha$ was 0.78 in our study.

\section{Statistical analyses}

All data analyses were conducted using SPSS version 22 . Descriptive statistics were used to describe the general characteristics and variables. Linearity was verified through scatterplot before performing Pearson's correlation analysis and multiple regression analysis. Pearson's correlation analyses were performed for perceived health status, occupational stress, sleep quality, and motives for food choices. Step-wise multiple regression analyses were used to examine factors influencing perceived health status. The multivariate linear regression was adjusted for general characteristics such as age, gender, level of education, living arrangements, and the number of illnesses. Statistical significance was set at a $p$-value of $<0.05$.

\section{Results}

\section{Characteristics of the participants}

Of 175 participants who completed the survey, 144 (82.3\%) participants were female and 31 (17.7\%) were male, with a mean age of $72.76 \pm 4.41$ years, as shown in Table 1. Of these, $59.5 \%$ of participants had received elementary school education or lower and $44 \%$ of participants lived with a spouse. The economic status of approximately half of the participants was at the middle level (50.3\%). Concerning place of work, our results showed that most participants $(88.0 \%)$ worked indoors. The participants worked primarily in the fields of food trimming, paper bag making, cafeteria service in school, and courier delivery. In total, $66.3 \%$ of participants reported having
Table I Characteristics of the participants

\begin{tabular}{|c|c|c|}
\hline Characteristics & $\begin{array}{l}\text { Mean } \pm \text { SD } \\
\text { or Number } \\
\text { (percentage) }\end{array}$ & $\begin{array}{l}\text { Number of } \\
\text { chronic } \\
\text { illnesses, } \\
\text { mean (SD) }\end{array}$ \\
\hline Age, years, mean (SD) & $72.76(4.4 I)$ & \\
\hline $\begin{array}{l}\text { 65-74, n (\%) } \\
\geq 75, \mathrm{n} \mathrm{( \% )}\end{array}$ & $\begin{array}{l}\mathrm{II}(65.7) \\
60(34.3)\end{array}$ & \\
\hline Female, n (\%) & I44 (82.3) & \\
\hline $\begin{array}{l}\text { Level of education, } \mathrm{n}(\%) \\
\text { Elementary school or lower } \\
\text { Middle school } \\
\text { High school or above }\end{array}$ & $\begin{array}{l}104(59.5) \\
37(21.1) \\
34(19.4)\end{array}$ & \\
\hline $\begin{array}{l}\text { Living arrangements, } \mathrm{n}(\%) \\
\text { With spouse } \\
\text { Solitary } \\
\text { With children or relatives }\end{array}$ & $\begin{array}{l}77(44.0) \\
69(39.4) \\
29(16.6)\end{array}$ & \\
\hline $\begin{array}{l}\text { Economic status level, n (\%) } \\
\text { Upper } \\
\text { Middle } \\
\text { Lower }\end{array}$ & $\begin{array}{l}2(1.1) \\
88(50.3) \\
85(48.6)\end{array}$ & \\
\hline $\begin{array}{l}\text { Place of work, n (\%) } \\
\text { Indoor } \\
\text { Outdoor }\end{array}$ & $\begin{array}{l}154(88.0) \\
21(12.0)\end{array}$ & \\
\hline Number of illnesses, mean (SD) & $1.15(1.12)$ & \\
\hline $\begin{array}{l}\text { Chronic illness, n (\%) } \\
\text { None } \\
\text { Above one }\end{array}$ & $\begin{array}{l}59(33.7) \\
116(66.3)\end{array}$ & \\
\hline $\begin{array}{l}\text { Perceived health status, mean } \\
\text { (SD) }\end{array}$ & $3.48(0.8)$ & \\
\hline KOSS-SF, mean (SD) & $31.49(11.5)$ & \\
\hline $\begin{array}{l}\text { KFI category, n (\%) } \\
\text { Robust (KFI 0-2) } \\
\text { Pre-frail (KFI 3-4) } \\
\text { Frail (KFI } \geq 5)\end{array}$ & $\begin{array}{l}146(83.4) \\
27(15.5) \\
2(1.1)\end{array}$ & $\begin{array}{l}1.02(0.9) \\
1.59(1.5) \\
3.50(0.7)\end{array}$ \\
\hline $\begin{array}{c}\text { PSQI category, n (\%) } \\
\text { Good (PSQI <5) } \\
\text { Poor (PSQI } \geq 5 \text { ) }\end{array}$ & $\begin{array}{l}101(57.7) \\
74(42.3)\end{array}$ & \\
\hline
\end{tabular}

Abbreviations: KFI, Korean frailty index; KOSS-SF, Korean occupational stress scale short-form; PSQI, Pittsburgh sleep quality index.

one or more chronic illnesses (mean for number of chronic illness, $1.15 \pm 1.12$ ). The mean score for participants' perceived health status was $3.48 \pm 0.80$ (score range, $1-5$ ). The level of occupational stress (KOSS-SF) was $31.49 \pm 11.50$ (range, 0-100). Participants were categorized according to frailty, as follows: robust (KFI score, 0-2), pre-frail (KFI 
score, 3-4), and frail (KFI score, $\geq 5$ ), with $83.4 \%$ of participants categorized as robust. Over half the participants $(57.7 \%)$ reported good sleep quality (PSQI <5).

\section{Correlations}

Table 2 shows the correlations for perceived health status, occupational stress, frailty, sleep quality, and motives for food choices. KOSS-SF $(r=-0.195, p<0.001)$, KFI $(r=-0.468$, $p<0.001)$, and PSQI $(r=-0.306, p<0.001)$ showed significant negative correlations with perceived health status. Conversely, 5 motives for food choices (health, weight control, price, sensory appeal, and mood) were positively correlated with perceived health status.

\section{Multivariate linear regression analyses}

Factors that influenced perceived health status among participants are shown in Table 3. Multivariate linear regression analyses of significant variables for correlation analysis in relation to occupational stress, frailty, sleep quality, 5 motives for food choices, and general characteristics such as age, gender, education level, and numbers of chronic illnesses were performed to identify the factors influencing the perceived health status of elderly workers. The analysis showed that the prediction model of perceived health status among elderly workers was significant $(\mathrm{F}=25.04, p<0.001)$. The explanatory power was $30.5 \%$. Factors influencing perceived health status were found to be KFI $(\beta=-0.420, p<0.001)$, KOSS-SF $(\beta=-0.195$,

Table 2 Correlations among perceived health status, occupational stress, frailty, sleep quality, and food choice motives for food choices

\begin{tabular}{|l|l|}
\hline Variables & Perceived health status \\
\hline KOSS-SF & $-0.195^{* *}$ \\
KFI & $-0.468^{* *}$ \\
PSQI & $-0.306^{* *}$ \\
FCM-Health & $0.236^{* *}$ \\
FCM-Weight control & $0.179^{*}$ \\
FCM-Price & $0.175^{*}$ \\
FCM-Sensory appeal & $0.296^{* *}$ \\
FCM-Mood & $0.279^{* *}$ \\
FCM-Familiarity & -0.002 \\
FCM-Convenience & 0.025 \\
FCM-Natural content & 0.148 \\
FCM-Ethical concerns & 0.141 \\
\hline
\end{tabular}

Notes: $* P<0.05, * * P<0.01$.

Abbreviations: FCM, food choice motives; KFI, Korean frailty index; KOSS-SF, Korean occupational stress scale short-form; PSQI, Pittsburgh sleep quality index. $p<0.001)$, and sensory appeal motives for food choices $(\beta$ $=0.240, p<0.001)$.

\section{Discussion}

Our study results showed that perceived health status among the elderly workers was related to occupational stress, frailty, sleep quality, and motives for food choices. With the number of elderly people increasing in many OECD countries and the number of elderly people growing rapidly in Japan and South Korea, ${ }^{1}$ healthcare providers need to identify the health problems of the elderly and provide interventions when needed. Although the social security system is well-established, the working period of the elderly increases as the life span increases; the issues of working and health problems among elderly populations are therefore becoming increasingly important. Healthcare providers need to pay attention to the health issues of the growing number of elderly workers, and in that respect, this study adds to the field of research focused on identifying the subjective health status and influencing factors of older workers.

Perceived health status showed a negative correlation with occupational stress. Occupational stress concerns physical and psychological responses when the occupational conditions do not coincide with the capabilities, resources, and needs of elderly workers. ${ }^{23}$ Most of the elderly workers were "blue collar" workers employed in cleaning, security, construction, and public work. ${ }^{3}$ It is likely that there will be greater social and psychological stress, when combined with vulnerability, among the elderly in the work environment. ${ }^{2}$ Many elderly workers are vulnerable to occupational challenges because of the large physical work load and psychological impact of their job. ${ }^{4}$ Our findings are consistent with psychological occupational demands having a negative effect on health behaviors. ${ }^{11}$ Considering the participants in our study were vulnerable due to occupational characteristics and aging, occupational stress may have negatively affected their health status. In particular, temporary blue-collar workers lack the opportunity to conduct regular medical examinations from their workplaces and will require close attention from health professionals as they may suffer from occupational vulnerabilities due to aging.

Perceived health status was negatively associated with frailty in the present study. A previous study that investigated frailty of community-dwelling elderly individuals reported pre-frail and frail rates of which over half were higher than our results. ${ }^{13}$ In one study involving 
Table 3 Factors influencing perceived health status

\begin{tabular}{|l|l|l|l|l|l|}
\hline Variables & B & P-value & SE & $\boldsymbol{\beta}$ & t \\
\hline KFI & -0.268 & $<0.001$ & 0.041 & -0.420 & -6.485 \\
KOSS-SF & -0.013 & $<0.001$ & 0.004 & -0.195 & -3.045 \\
FCM-Sensory appeal & 0.188 & $<0.001$ & 0.051 & 0.240 & 3.695 \\
\cline { 2 - 5 } & $\mathrm{R}^{2}=0.305$, adjusted $\mathrm{R}^{2}=0.293, \mathrm{~F}=25.04$, and $p<0.001$ \\
\hline
\end{tabular}

Note: The model was adjusted for age, gender, level of education level, living arrangements, and number of illnesses.

Abbreviations: FCM, food choice motives; KFI, Korean frailty index; KOSS-SF, Korean occupational stress scale short-form.

community elderly residents, most participants were found to have more than one chronic disease. ${ }^{3}$ However, our findings indicated that the pre-frail and frail rates were lower than those in community-dwelling older adults, ${ }^{13}$ even though over $60 \%$ of elderly workers reported having more than one chronic illness. Elderly workers are most likely healthier than community-dwelling older adults; this result can be attributed to the greater likelihood that seniors with serious health problems would not be able to physically perform work. This healthy worker selection bias should thus be taken into account when interpreting the conclusions of our results, ${ }^{22}$ as the participants of this study were selected as a convenience sample of community-resident elderly workers. As age increases, the working population may remain relatively healthy compared to non-workers of the same age. Thus, it will be necessary to reaffirm the presence of the healthy worker effect by conducting comparison studies that examine the difference in perceived health status between elderly workers and age-matched non-working controls.

In one survey investigating elderly workers' health status, the results showed that some of the elderly workers reported having a chronic health condition, and back pain or other musculoskeletal disorders were most commonly reported. $^{20}$ One qualitative study of elderly workers reported that the workers had exacerbations in their disease conditions and that they were not provided with appropriate hospital treatment. ${ }^{29}$ In another study, elderly workers with health issues showed a high incidence of depression and low quality of life. ${ }^{2}$ Moreover, many elderly workers were found to have chronic illnesses, and older adults with chronic diseases have a high risk of frailty. ${ }^{8}$ Although most participants were categorized into the robust group, more than half of the participants had chronic illnesses that were possibly related to frailty. Therefore, frailty prevention can be an emerging issue among elderly workers, and elderly workers should be engaged in frailty prevention strategies to improve their health status.

Perceived health status was negatively related to the PSQI in our study, which means that perceived health status was positively associated with sleep quality. Regarding sleep quality, our results support the previous findings that showed sleep quality can affect physical activity, psychological problems such as depression ${ }^{14}$ and perceived health status. ${ }^{30}$ In elderly individuals, sleep challenges involve difficulty in sleeping, a short sleep duration, and prolonged sleep latency. ${ }^{30}$ Sleep management is an important factor for senior workers as poor sleep quality can increase the risk of accidents, chronic diseases, and negative health conditions. ${ }^{31}$ A correlation between sleep and frailty among older adults has previously been reported, showing that poor sleep quality was associated with a greater frailty status. ${ }^{32}$ As frailty becomes increasingly prevalent with advancing age, older adults were found to be more likely to have an increased frailty status and poor sleep quality. ${ }^{33}$ In the present study, poor quality sleep affected over $40 \%$ of the participants, which was similar to the results of a previous study. ${ }^{15}$ Sleep quality is associated with health status and activity performance; ${ }^{14,30,31}$ therefore, for older adults to continue to work safely and continuously, healthcare professionals need to be concerned with ensuring good sleep quality for their elderly patients.

To our knowledge, a study involving motives for food choices related to health status has not been previously undertaken for elderly workers. Our research results demonstrate that health, weight control, price, sensory appeal (taste and smell), and mood in relation to motives for food choices were significantly associated with perceived health status. The results are inconsistent regarding food choice studies on elderly individuals. A previous study reported that health, taste, price and time to the grocery store were significant influential factors regarding food choices in older adults. ${ }^{34}$ Another study indicated that health, mood, sensory appeal, 
and motives for food choice were associated with personal well-being. ${ }^{35}$ A systematic review by Cruwys et al documented that food choice behaviors can be affected by many individual, social, and contextual factors. ${ }^{19}$ Regarding socio-economic status, those with a high income rated a meal that was healthy and flavorful to be more important than did those with a lower income. ${ }^{34}$ Another study reported that price was the most important factor for elderly individuals with regard to choosing their food. ${ }^{35}$ As such, economic determinants including wages also have an influence on food choices. In addition to the price, the motivation for selecting food that affects subjective health conditions was sensory appeal.

Through chemosensory changes, older adults experience increasing taste and smell sensitivities. ${ }^{36}$ Chemosensory changes can affect sensory appeal and therefore influence the food choice of elderly individuals. In a study that investigated working circumstances and high adherence to medication, few participants adhered to food intakes among the elderly workers on account of the need to focus on their work. ${ }^{11}$ Because of time shortages, occupational vulnerability conditions, these mood factors affecting food choices may have an influence on working older individuals. In this study, most participants were female and had increased risks for type 2 diabetes and metabolic diseases, affecting their decisions regarding weight control and food consumption. ${ }^{37}$ The convenience of food availability did not affect the health status of participants in our study. However, one study in low-income urban elderly individuals indicated that difficulty in preparing food and the time it took to get to the grocery store contributed to food intake. ${ }^{17,34}$ Thus, how much food convenience affects the health status of older individuals is controversial. Proper food intake is necessary to stay healthy. Since price and sensory appeal are identified as factors that may affect the motivation of older workers to choose food, it will be helpful to consider these food-selective factors when promoting the health of elderly workers.

To determine the influencing factors on perceived health status, we used a multivariate regression analysis model. Our results indicated that occupational stress, frailty, and sensory appeal motives for food choices were significant factors concerning perceived health status compared to other factors. Healthcare professionals and policy makers need to consider these key factors in improving elderly worker's health and developing effective health promotion interventions. The model indicated that approximately $30 \%$ of participants were significantly affected by factors concerning perceived health status. Because perceived health status includes not only physical but also psychological aspects, further studies should consider more diverse emotional factors in addition to the variables noted in our study.

To our knowledge, our study is the first to show the key factors such as occupational stress, frailty, sleep quality, and motives for food choices on the perceived health status of elderly workers in Korea. Employment can enhance the economic status and the quality of life among older adults. Considering the increasing numbers of elderly workers, interventions are needed to improve occupational stress, sleep quality, and motives for food choices to prevent frailty and improve health status. Our findings could provide basic data for health education and program development for elderly workers.

\section{Limitations}

This study has several limitations. First, this research method is subject to external validity risks as it used a convenience sampling scheme. Study subjects were selected only from a Community Senior Club in an urban setting, so the generalization of our research to the entire population of interest is problematic. We suggest that future large-scale, representative studies that utilize random sampling may help reduce the selection biases of convenience sampling and the healthy worker effect. Secondly, our study did not explore the effects on perceived health status in relation to gender differences, specific old-age groups, and occupational characteristics. To achieve a comprehensive understanding of health in elderly workers, a comparison of gender ratio and socioeconomic status factors should be assessed in future research. Finally, to reduce the healthy worker effect, it will be necessary to conduct comparison studies that examine the difference in perceived health status between elderly workers and age-matched non-working controls.

\section{Conclusion}

Life expectancy has increased with the advances of medical science and technology. Given the global trend in aging populations, the elderly in the future may work longer after their retirement for various reasons. Healthcare providers and policy makers need to consider greater promotion and focus on elderly workers' health. Our findings show that perceived health status relates to occupational stress, frailty, sleep quality, and motives for 
food choices. Effective interventions to manage older adult occupational stress, sleep, and food intake are may be important in preventing frailty and maintaining good levels of health in this working elderly population.

\section{Acknowledgment}

This work was supported by the National Research Foundation of Korea (NRF) grant funded by the Korea government (MSIT) (No. 2018R1C1B5085248).

\section{Disclosure}

The authors report no conflicts of interest in this work.

\section{References}

1. Statistics Korea Database. Percentage of people aged 65 or older by OECD countries; Korea. Available from: http://210.179.230. $152: 8083 / \mathrm{statHtml} / \mathrm{statHtml}$.do? orgId=358\&tblId=DT_IGJ001_ 3\&conn_path=I2. Accessed July 26, 2019.

2. Kim DB, Yoo BS, Lee EJ. The influence of the work satisfaction on the life satisfaction for the working elderly in Seoul: a mediating effect of self-esteem. $J$ Welf Aged. 2013;60:201-236.

3. Korea Institute for Health and Social Affairs. 2017 National elderly survey; Korea: KIHASA; 2017. Available from: http://www.prism. go.kr/homepage/entire/retrieveEntireDetail.do?pageIndex= 1\&research_id=1351000-201700250\&leftMenuLevel=160\&cond research name $=\% \mathrm{~EB} \% 85 \% \mathrm{~B} 8 \% \mathrm{EC} \% 9 \mathrm{D} \% \mathrm{~B} 8 \% \mathrm{EC} \% 8 \mathrm{~B} \% \mathrm{~A} 4 \% \mathrm{ED} \%$ $83 \% 9 \mathrm{C} \% \mathrm{EC} \% \mathrm{~A} 1 \% \mathrm{~B} 0 \% \mathrm{EC} \% 82 \% \mathrm{AC} \&$ cond_research_start_date $=$ $\&$ cond_research_end_date $=\&$ pageUnit $=10 \&$ cond_order $=3$. Accessed May $24,2018$.

4. Leijten FR, van Den Heuvel SG, van der Beek AJ, et al. Associations of work-related factors and work engagement with mental and physical health: a 1-year follow-up study among older workers. J Occup Rehabil. 2015;25(1):86-95. doi:10.1007/s10926-014-9525-6

5. Park J, Yoon S, Moon SS, Lee KH, Park J. The effects of occupational stress, work-centrality, self-efficacy, and job satisfaction on intent to quit among long-term care workers in Korea. Home Health Care Serv Q. 2017;36(2):96-111. doi:10.1080/ 01621424.2017 .1333479

6. Kwon MH, Lee JS. The effects of occupational characteristics and leisure activities participation of elderly workers on health. $J$ Korean Soc Occup Ther. 2018;26(2):33-42. doi:10.14519/jksot.2018.26.2.03

7. Ahn SY, Lee HJ. The impact of transitions of labour market status on health for aged over 65 in Korea. J Korean Geriatr Soc. 2015;35 (3):745-764.

8. Buckinx F, Rolland Y, Reginster JY, et al. Burden of frailty in the elderly population: perspectives for a public health challenge. Arch Public Health. 2015;73(1):19. doi:10.1186/s13690-015-0068-x

9. Clegg A, Young J, Iliffe S, Rikkert MO, Rockwood K. Frailty in elderly people. Lancet. 2013;381(9868):752-762. doi:10.1016/ S0140-6736(12)62167-9

10. Fried LP, Ferrucci L, Darer J, Williamson JD, Anderson G. Untangling the concepts of disability, frailty, and comorbidity: implications for improved targeting and care. J Gerontol A Biol Sci Med Sci. 2004;59(3):255-263. doi:10.1093/gerona/59.3.M255

11. Dickson VV, Howe A, Deal J, McCarthy MM. The relationship of work, self-care, and quality of life in a sample of older working adults with cardiovascular disease. Heart Lung. 2012;41(1):5-14. doi:10.1016/j.hrtlng.2011.09.012

12. Farrow A, Reynolds F. Health and safety of the older worker. Occup Med. 2012;62(1):4-11. doi:10.1093/occmed/kqr148
13. Bandeen-Roche K, Seplaki CL, Huang J, et al. Frailty in older adults: a nationally representative profile in the United States. J Gerontol $A$ Biol Sci Med Sci. 2015;70(11):1427-1434. doi:10.1093/gerona/ glv133

14. Smagula SF, Stone KL, Fabio A, Cauley JA. Risk factors for sleep disturbances in older adults: evidence from prospective studies. Sleep Med Rev. 2016;25:21-30. doi:10.1016/j.smrv.2015.01.003

15. Wu CY, Su TP, Fang CL, Chang MY. Sleep quality among community-dwelling elderly people and its demographic, mental, and physical correlates. J Chin Mel Assoc. 2012;75(2):75-80. doi:10.1016/j. jcma.2011.12.011

16. Grov EK, Fosså SD, Dahl AA. Insomnia in elderly cancer survivors-a population-based controlled study of associations with lifestyle, morbidity, and psychosocial factors. Results from the health survey of North-Trøndelag County (HUNT-2). Support Care Cancer. 2011;19 (9):1319-1326. doi:10.1007/s00520-010-0948-0

17. Hyun HS, Lee I. Nutritional status and risk factors for malnutrition in low-income urban elders. J Korean Acad Nurs. 2014;44(6):708-716. doi:10.4040/jkan.2014.44.6.708

18. Yannakoulia M, Ntanasi E, Anastasiou CA, Scarmeas N. Frailty and nutrition: from epidemiological and clinical evidence to potential mechanisms. Metabolism. 2017;68:64-76. doi:10.1016/j. metabol.2016.12.005

19. Cruwys T, Bevelander KE, Hermans RC. Social modeling of eating: a review of when and why social influence affects food intake and choice. Appetite. 2015;86:3-18. doi:10.1016/j.appet.2014.08.035

20. Schofield DJ, Shrestha RN, Passey ME, Earnest A, Fletcher SL. Chronic disease and labour force participation among older Australians. Med J Aust. 2008;189(8):447. doi:10.5694/j.13265377.2008.tb02119.x

21. Abu-Bader SH, Rogers A, Barusch AS. Predictors of life satisfaction in frail elderly. J Gerontol Soc Work. 2003;38(3):3-17. doi:10.1300/ J083v38n03_02

22. Chowdhury R, Shah D, Payal AR. Healthy worker effect phenomenon: revisited with emphasis on statistical methods-A review. Indian J Occup Environ Med. 2017;21(1):2-8. doi:10.4103/ijoem. IJOEM_53_16

23. Chang SJ, Koh SB, Kang D, et al. Developing an occupational stress scale for Korean employees. Korean J Occup Environ Med. 2005;17 (4):297-317. doi:10.35371/kjoem.2005.17.4.297

24. Choi YI, Kim EJ, Park EY. Validity of the Korean occupational stress scale in occupational therapists. J Korea Contents Assoc. 2011;11 (7):225-233. doi:10.5392/JKCA.2011.11.7.225

25. Hwang HS, Kwon IS, Park BJ, et al. The validity and reliability of Korean frailty index. J Korean Geriatr Soc. 2010;14(4):191-202. doi:10.4235/jkgs.2010.14.4.191

26. Buysse DJ, Reynolds CF 3rd, Monk TH, Berman SR, Kupfer DJ. The Pittsburgh sleep quality index: a new instrument for psychiatric practice and research. Psychiatry Res. 1989;28(2):193-213. doi:10.1016/0165-1781(89)90047-4

27. Steptoe A, Pollard TM, Wardle J. Development of a measure of the motives underlying the selection of food: the food choice questionnaire. Appetite. 1995;25:267-284. doi:10.1006/appe.19 95.0061

28. Speake DL, Cowart ME, Pellet K. Health perceptions and lifestyles of the elderly. Res Nurs Health. 1989;12(2):93-100. doi:10.1002/ nur.4770120206

29. Kweon YR, Kim MY. Elderly workers living in urban areas and their experiences in managing health. Korean J Adult Nurs. 2014;66:3754. doi:10.7475/kjan.2016.28.5.514

30. Park YH. Physical activity and sleep patterns in elderly who visited a community senior center. J Korean Acad Nurs. 2007;37(1):5-13. doi:10.4040/jkan.2007.37.1.5

31. Luyster FS, Strollo PJ, Zee PC, Walsh JK. Sleep: a health imperative. Sleep. 2012;35(6). doi:10.5665/sleep.1846 
32. Ensrud KE, Blackwell TL, Redline S, et al. Sleep disturbances and frailty status in older community-dwelling men. $J$ Am Geriatr Soc. 2009;57(11):2085-2093. doi:10.1111/j.1532-5415.2009.02490.x

33. Del Brutto OH, Mera RM, Sedler MJ, et al. The effect of age in the association between frailty and poor sleep quality: a population-based study in community-dwellers (The Atahualpa Project). J Am Med Dir Assoc. 2016;17(3):269-271. doi:10.1016/j.jamda.2015.12.009

34. Kamphuis CB, de Bekker-Grob EW, van Lenthe FJ. Factors affecting food choices of older adults from high and low socioeconomic groups: a discrete choice experiment. Am J Clin Nutr. 2015;101 (4):768-774. doi:10.3945/ajen.114.096776
35. Lesakova D. Health perception and food choice factors in predicting healthy consumption among elderly. Acta Univ Agric Fac Agron. 2018;66(6):1527-1534. doi:10.11118/actaun2018660 61527

36. Coa K, Epstein JB, McManus K, Moskowitz B. Dietary changes and food preferences experienced by older adult cancer patients and the impact on health outcomes. Curr Res Nutri Food Sci J. 2018;6 (2):263-272. doi:10.12944/CRNFSJ.6.2.02

37. van Meer F, Charbonnier L, Smeets PA. Food decision-making: effects of weight status and age. Curr Diab Rep. 2016;16(9):84. doi:10.1007/s11892-016-0773-z
Clinical Interventions in Aging

\section{Publish your work in this journal}

Clinical Interventions in Aging is an international, peer-reviewed journal focusing on evidence-based reports on the value or lack thereof of treatments intended to prevent or delay the onset of maladaptive correlates of aging in human beings. This journal is indexed on PubMed Central, MedLine, CAS, Scopus and the Elsevie
Dovepress

Bibliographic databases. The manuscript management system is completely online and includes a very quick and fair peer-review system, which is all easy to use. Visit http://www.dovepress.com/ testimonials.php to read real quotes from published authors. 